\title{
A fatal case of creosote poisoning
}

\author{
Clive E. Bowman \\ B.Sc., M.R.C.P.
}

\author{
MARK F. MUHLEMAN \\ M.R.C.P.
}

\author{
EWAN WALTERS \\ B.Sc., M.B.Ch.B.
}

Department of Medicine, Southmead Hospital, Westbury-on-Trym, Bristol BS10 5NB

\begin{abstract}
Summary
A case of fatal creosote poisoning is described. On presentation, extensive oropharyngeal ulceration was noted and gastric lavage withheld. Post-mortem examination showed an intact oesophagus and stomach.
\end{abstract}

KEY WORDS: kidney failure, acute acidosis.

\section{Introduction}

Industrial creosote, commonly used for wood preservation, is a distillate of coal and wood tars. Phenols and cresols are responsible for its toxicity. Management of creosote poisoning is based on experience from cases poisoned by cleaning agents such as Lysol, now largely withdrawn, which are much more concentrated phenolic solutions. To our knowledge there is not a full published account of fatal creosote poisoning.

\section{Case report}

A 70-year-old man was found unconscious with a cup of creosote beside him. On admission he was unconscious responding only to painful stimuli, rectal temperature $34^{\circ} \mathrm{C}$, centrally cyanosed and shocked with a pulse of $60 / \mathrm{min}$, blood pressure $60 / 40$ $\mathrm{mmHg}$. His respiratory effort was poor and on auscultation widespread crackles were heard. Creosote and vomitus stained his face and clothing. There was obvious extensive ulceration of the oropharynx.

Endotracheal intubation and artificial ventilation was instituted immediately. Gastric lavage was not performed because of presumed oesophageal ulceration. Forty-five minutes following presentation and initial resuscitation (including intubation and ventilation), measurements showed $\mathrm{pH} 7 \cdot 15, \mathrm{Po}_{2} 204$ $\mathrm{mmHg}, \mathrm{PCO}_{2} 24 \mathrm{mmHg}$, bicarbonate $9.3 \mathrm{mmol} / \mathrm{l}$, base excess $-16.2 \mathrm{mmol} / \mathrm{l}$. He was treated with gradual rewarming, intravenous amoxycillin and hydrocortisone (200 $\mathrm{mg}$ 4-hourly). Two litres of normal saline were infused over the first $2 \mathrm{hr}$ of admission which raised the central venous pressure from $-2 \mathrm{cmH}_{2} \mathrm{O}$ to $+5 \mathrm{~cm}$ (using mid axillary line as zero). His blood pressure remained low but with an infusion of dopamine rose to $140 / 80 \mathrm{mmHg}$. Over the first $8 \mathrm{hr}$ of admission an average of $30 \mathrm{ml} / \mathrm{hr}$ of smokey coloured urine was excreted. Thereafter urine output fell gradually in spite of vigorous therapy with frusemide and mannitol.

Five hours after admission arterial blood showed pH 7.09, $\mathrm{PO}_{2} 82 \mathrm{mmHg}, \mathrm{PCO}_{2} 22 \mathrm{mmHg}, \mathrm{HCO}_{3} 6.9$. Base excess -17.8 after which bicarbonate was given. The patient became anuric and after $30 \mathrm{hr}$ death occurred.

At post-mortem about 1 litre of fluid, mainly creosote, was found in the stomach. The oesophageal and gastric mucosa were strained brown but were well preserved. Petechial haemorrhages were noted over the serosal surface of the lower jejunum, ileum and also over the pericardium. Histology of oesophageal and gastric mucosa showed no ulceration. Renal histology showed acute tubular necrosis and the liver showed degeneration and necrosis of hepatocytes with minimal inflammation.

\section{Discussion}

Phenols denature and precipitate proteins; they are general cellular poisons, for which, once absorbed, there is no specific antidote.

When ingested, absorption is initially rapid and then subsequently slower probably due to local vascular damage (Locket, 1957). Early poisoning may be characterized by a respiratory alkalosis due to a salicylate-like stimulation of the respiratory centre (Dreisbach, 1977), thereafter an acidosis of mixed aetiology occurs. Methaemoglobinaemia may develop. Death is a result of multi-organ failure. 
Prevention of absorption by gastric lavage clearly is the most effective treatment. Addition of vegetable oils to the lavage fluid by dissolving phenols should minimize absorption (Burston, 1970). Traditionally oesophageal integrity has been assessed indirectly by the condition of the oropharynx, but in the presented case this proved misleading, It seems likely that ulceration of the oesophagus and stomach did not occur in this case because of the greater dilution of phenols and cresols in creosote compared with, for example, Lysol. Supportive evidence comes from veterinary experience, chronic ingestion of creosote in sheep leads to death from multi-organ failure, whereas purer phenol preparations cause violent corrosive effects (Clarke and Clarke, 1975). Therefore in creosote poisoning, oropharyngeal ulceration is an unreliable indicator of gastrooesophageal integrity. Expert endoscopic assessment and the possible alternative of lavage via a gastrostomy should be $\stackrel{\bar{Q}}{\frac{2}{2}}$ considered.

\section{Acknowledgments}

We thank Dr N. Malcolm for permission to report this case and Dr A. Savage for performing the post-mortem examination.

\section{References}

BURSTON, G.R. (1970) Self Poisoning, p. 148. Lloyd Luke, London Clarke, E.G.C. \& Clarke, M.L. (1975) Veterinary Toxicology. 143. Bailliere Tindall, London.

DreisbaCH, R.H. (1977) Handbook of Poisoning. p. 253, 9th edn. Lange, Los Altos, California.

LOCKET, S. (1957) The clinical diagnosis and treatment of poisoning. In: Clinical Toxicology, p. 493. Henry Kimpton, London.

(Accepted 8 June 1983) 